\title{
EVALUATION OF EFFICACY OF INDICES IN PSORIASIS IN RELATION TO SEVERITY AND IMPROVEMENT IN THERAPY
}

\author{
Venkata Krishna Ananthula1, K. Narasimha Prasad², J. V. D. S. Prasad 3 , Swapna Priya ${ }^{4}$
}

${ }_{1}^{1}$ Associate Professor, Department of DVL, Osmania Medical College.

${ }^{2}$ Assistant Professor, Department of DVL, Osmania Medical College.

3 Professor, Department of DVL, Osmania Medical College.

4 Junior Resident, Department of DVL, Osmania Medical College.

\begin{tabular}{l}
\hline ABSTRACT \\
BACKGROUND \\
Psoriasis is a chronic disfiguring, inflammatory and proliferative condition of the skin in which both the genetic and \\
environmental factors have a critical role. Many environmental factors like the trauma, infection, drugs, sunlight, metabolic factors, \\
psychogenic factors, alcohol and smoking have been linked to psoriasis and have been implicated in initiation of disease process and \\
exacerbation of pre-existing disease treatment.
\end{tabular}

\section{METHODS}

The present study is conducted on a total of 40 patients, who presented with chronic plaque psoriasis to Department of DVL, Osmania General Hospital, Hyderabad, from September 2014 to July 2015. All the 40 cases were subjected to thorough clinical examination and investigations. We performed the calculations of BSA, PGA, PASI, PLASI in the cases.

\section{RESULTS}

The mean results of BSA, PGA, PASI, PLASI before and after 8 weeks of treatment with methotrexate were calculated. The mean score before and after treatment therapy differed significantly $(\mathrm{p}<0.0001)$. Largest absolute difference was found with PLASI (35.1) followed by PASI (19), BSA (12.8), PGA (4). Largest relative difference was found with PLASI (86.32\%), PASI (84.16\%), PGA (80\%) and BSA (75.75\%).

\section{CONCLUSIONS}

Strength of each correlation was compared. The correlation between PLASI and PASI ( $\mathrm{r}=0.932)$ was significantly stronger than correlation between any other two indices. Correlation between PLASI and BSA ( $r=0.593)$ was found to be weakest among all other indices. Correlation with PGA with PASI, PLASI was weaker than correlation between PASI and PLASI. In our study, the slope of the regression for PLASI $(b=3.319)$ vs. PASI $(b=2.462)$ indicates that PLASI is more accurate than PASI. In the regression analyses, all other slopes were less than unity indicating that the severity differentiation was inferior, especially when BSA was involved in the analysis.

\section{KEYWORDS}

Psoriasis, BSA, PGA, PASI, PLASI.

HOW TO CITE THIS ARTICLE: Ananthula VK, Prasad KN, Prasad JVDS, et al. Evaluation of efficacy of indices in psoriasis in relation to severity and improvement in therapy. J. Evolution Med. Dent. Sci. 2016;5(74):5507-5514, DOI: 10.14260/jemds/2016/1244

\section{INTRODUCTION}

Psoriasis is a chronic disfiguring, inflammatory and proliferative condition of the skin in which both the genetic and environmental factors have a critical role. Many environmental factors like the trauma, infection, drugs, sunlight, metabolic factors, psychogenic factors, alcohol and smoking have been linked to psoriasis and have been implicated in initiation of disease process and exacerbation of pre-existing disease. Many measures are established to evaluate severity of skin disease. In psoriasis clinical trials, the most common measure is Psoriasis Area Severity Index (PASI).

Financial or Other, Competing Interest: None.

Submission 09-08-2016, Peer Review 01-09-2016,

Acceptance 08-09-2016, Published 15-09-2016.

Corresponding Author:

Dr. Venkata Krishna Ananthula,

H. No. 21-41,

Vivekananda Nagar,

Dilsukhnagar,

Hyderabad-500060, Telangana.

E-mail: drvkananthula@gmail.com

DOI: $10.14260 /$ jemds/2016/1244
Several years later psoriasis log based area and severity index (PLASI) were introduced. This study investigates the strengths of these individual measures and aims to select best fitting measure to describe the severity and improvement after treatment.

\section{Measures to Assess Psoriasis}

To measure disease severity and effectiveness of therapies, good clinical psoriasis measures are a necessity. The purpose of this study was to identify all clinical measures of psoriasis severity and outcome in use and to evaluate the quality of these measures. We identified 53 separate clinical measures, which were regrouped into 4 measures for quality analysis.

The Psoriasis Area and Severity Index is the most commonly used clinical measure in research, but it has substantial limitations such as low response distribution, no consensus on interpretability, and low responsiveness in mild disease. Nevertheless, because of its widespread use the Psoriasis Area and Severity Index permits some degree of comparison of results among clinical trials. 
All Retrieved Clinical Outcome Measures Re-Grouped in 4 Main Clinical Severity and Outcome Measures for Analysis

1. Body Surface Area (BSA).

2. Physician's/Psoriasis Global Assessment (PGA) Static assessment.

3. Psoriasis Area and Severity Index (PSI).

4. Psoriasis Long Based Area and Severity Index (PLASI).

\section{Body Surface Area (BSA)}

Most commonly used to estimate the BSA is the "rule of nines" (Ramsay and Lawrence, 1991). ${ }^{1}$ It is defined as $9 \%$ coverage for the head and neck, each arm, anterior and posterior leg as well as the four trunk quadrants respectively, leaving $1 \%$ for the genitalia. The BSA can also be estimated by the number of patients' hand areas affected, assuming that one "handprint" reflects approximately $1 \%$ of BSA.

BSA is arithmetic mean of the affected skin surface based on assumption that Head (H), the Upper Limbs (UL) 20\%, Trunk (T) 30\%, Lower Limbs (LL) 40\% of total body surface area.

The Formula for Calculation of BSA is:

$\mathrm{BSA}=0.1 * \mathrm{BSA}_{\mathrm{H}}+0.2 * \mathrm{BSA}_{\mathrm{UL}}+0.3 * \mathrm{BSA}_{\mathrm{T}}+0.4 * \mathrm{BSA}_{\mathrm{LL}}$

\section{PHYSICIAN GLOBAL ASSESSMENT}

Generally speaking, the PGA is an average assessment of all psoriatic lesions based on erythema, scale and induration. Typically, the PGA is a 5, 6 or 7-point ordinal rating ranging from "clear" to "very severe psoriasis." In addition to the different approaches to PGA, the PGA tool described in clinical trials varies widely. This variation has the potential to produce non-standardised results. The scales used range from 4 points to 10 points and although all typically evaluate the average erythema, plaque elevation and scale of all involved lesions.

\begin{tabular}{|c|c|c|}
\hline Grade & Description & Response \\
\hline 0 & Completely Clear & $\begin{array}{l}\text { No evidence of disease; } \\
100 \% \text { improvement CR }\end{array}$ \\
\hline 1 & Almost Clear & $\begin{array}{c}\text { Very significant } \\
\text { clearance } \\
(\geq 90 \% \text { to }<100 \%) ; \\
\text { only traces of disease } \\
\text { remain } \mathrm{PR}\end{array}$ \\
\hline 2 & Marked Improvement & $\begin{array}{c}\text { Significant improvement } \\
(\geq 75 \% \text { to }<90 \%) ; \\
\text { some evidence of disease } \\
\text { remains PR } \\
\end{array}$ \\
\hline 3 & Moderate Improvement & $\begin{array}{l}\text { Intermediate between } \\
\text { slight and marked } \\
\text { improvement; } \\
(\geq 50 \% \text { to }<75 \%) \text { PR } \\
\end{array}$ \\
\hline 4 & Slight Improvement & $\begin{array}{l}\text { Some improvement } \\
(\geq 25 \% \text { to }<50 \%) ; \\
\text { significant evidence of } \\
\text { disease remains SD }\end{array}$ \\
\hline 5 & No Change & $\begin{array}{c}\text { Disease has not changed } \\
\text { from } \\
\text { baseline condition } \\
(+<25 \%) \mathrm{SD}\end{array}$ \\
\hline 6 & $\begin{array}{c}\text { Worse Disease is Worse } \\
\text { than at Baseline } \\
\text { Evaluation }\end{array}$ & $\begin{array}{c}\text { By } \geq 25 \% \text { or more } \mathrm{PD} C \mathrm{CR} \\
=\text { complete response; } \\
\mathrm{PR}=\text { partial response; } \mathrm{SD} \\
=\text { stable disease; } \\
\mathrm{PD}=\text { progressive disease }\end{array}$ \\
\hline & $\begin{array}{r}\text { ntary Table 1: } \\
\text { Clinical Cor }\end{array}$ & $\begin{array}{l}\text { Global Assessment of } \\
\text { ynamic) }\end{array}$ \\
\hline
\end{tabular}

\section{STATIC PGA}

Rate Psoriasis Severity at each Time Point, for each Patient using Static PGA

- 6 - Severe psoriasis.

- 5 - Moderate-to-severe psoriasis.

- 4 - Moderate psoriasis.

- 3 - Mild-to-moderate psoriasis.

- 2 - Mild psoriasis.

- Psoriasis almost cleared.

- Clear (no lesions).

\section{Psoriasis Area and Severity Index (PASI)}

In 1978, the PASI was developed to assess the effects of retinoids in psoriasis (Fredriksson and Pettersson, 1979).2,3 The affected area and lesion characteristics are entered in a formula that results in a score from 0 to 72 .

A patient's Psoriasis Area and Severity Index (PASI) is a measure of overall psoriasis severity and coverage. It is a commonly-used measure in clinical trials for psoriasis treatments.

\section{PASI consists of Two Major Steps:}

1. Calculating the BSA (Body Surface Area) covered with lesions.

2. Assessment of the severity of lesions. The second step in turn consists of assessing lesions erythema (Redness), induration (Thickness) and scaling.

All calculations are combined into a single score (PASI Score) in the range of 0 (no psoriasis on the body) and up to 72 (the most severe case of psoriasis). Typically, the PASI would be calculated before, during and after a treatment period in order to determine how well psoriasis responds to the treatment.

These Values are Finally Entered in the Following Formula PASI $=0.1 \quad(\mathrm{Eh}+\mathrm{Ih}+\mathrm{Dh}) * \mathrm{Ah}+0.2 \quad(\mathrm{Eu}+\mathrm{Iu}+\mathrm{Du}) * \mathrm{Aul}+0.3$ $(\mathrm{Et}+\mathrm{It}+\mathrm{Dt}) * \mathrm{At}+0.4(\mathrm{El}+\mathrm{Il}+\mathrm{Dl}) \mathrm{Al}$

These Values are Finally Entered in the Following Formula PASI $=0.1 \quad(\mathrm{Eh}+\mathrm{Ih}+\mathrm{Dh})^{*} \mathrm{Ah}+0.2 \quad(\mathrm{Eu}+\mathrm{Iu}+\mathrm{Du}) * \mathrm{Aul}+0.3$ $(\mathrm{Et}+\mathrm{It}+\mathrm{Dt}) * \mathrm{At}+0.4(\mathrm{El}+\mathrm{Il}+\mathrm{Dl}) \mathrm{Al}$

\section{Psoriasis Log Based Area Severity Index (PLASI):}

The PLASI uses six BSA groupings (47 - 100\% - 6, 12 - 46\% - 5 , $11-12 \%-4,6-10 \%-3,3-5 \%-2,1-2 \%-1,0 \%-0)$ with finer partitioning for smaller extents of BSA affected.

This is supposed to reduce the error resulting from inaccurate estimation of BSA in patients with less extensive disease, also to increase sensitivity among patients with mildto-moderate disease in detecting changes in psoriasis severity. PLASI calculation is identical with PASI, but for a different score for extent of skin lesions, which is mentioned above. These values are a result of the logarithms of $x / 3(x=1-6)$ eg $10^{\wedge} 0 / 3=0,10^{\wedge} 1 / 3=2,10^{\wedge} 2 / 3=5, \ldots 10^{\wedge} 6 / 3=100$.

\section{MATERIAL AND METHODS}

The material for this study constituted 40 patients selected from Department of DVL, Osmania General Hospital, Hyderabad, from September 2014 to July 2015. The patients were selected based on following inclusion and exclusion criteria. 


\section{Inclusion Criteria}

Extensive plaque psoriasis not responsive to conventional therapy. Psoriasis that adversely affects the ability to maintain employment.

\section{Exclusion Criteria}

Active infectious disease or history of serious infection that could reactivate (such as TB). Man or woman contemplating conception Hepatic disease, abnormal liver function tests, active hepatitis, history of liver disease cirrhosis.

Severe haematologic abnormalities pregnancy lactation.

The patients fitting the criteria were selected and detailed history, clinical examination was carried out in all cases as per proforma attached.

\section{All Patients were Subjected to Detailed Investigations as} Follows

- Haematological investigations.

- Total leucocyte count.

- Differential leucocyte count.

- Erythrocyte sedimentation rate.

- Haemoglobin estimation.

- Blood sugar.

- Serological investigation.

- Liver function tests.

- Renal function tests.

- Serum proteins.

- Serum electrolytes.

- Radiological investigation.

- Chest X-ray.

- Ultrasonography in relevant cases.

\section{METHODOLOGY}

The patients taken into study were explained and consent was taken. The photographs of patients were taken before starting treatment in systemised manner shown as follows and 8 weeks following treatment.

The following 4 Indices were applied on each Patient Before and After Treatment

- Body surface area.

- Physician global assessment.

- Psoriasis area severity index.

- $\quad$ Psoriasis Log-Based Area Severity Index (PLASI).

Body Surface area Calculated as Follows:

Head $(\mathrm{H})$ represents $10 \%$, upper limbs (U) represents $20 \%$, trunk (T) $30 \%$ and lower extremities (L) $40 \%$ of total body surface area.

The Formula for Calculation is

$\mathrm{BSA}=0.1 \times \mathrm{BSA}_{\mathrm{H}}+0.2 \times \mathrm{BSA}_{\mathrm{U}}+0.3 \times \mathrm{BSA}_{\mathrm{T}}+0.4 \times \mathrm{BSA}_{\mathrm{L}}$

PGA (Physician Global Assessment) was given a Score each Point of Time, i.e. at Each Visit

- 6 - Severe psoriasis.

- 5 - Moderate-to-severe psoriasis.

- 4 - Moderate psoriasis.

- 3 - Mild-to-moderate psoriasis.

- 2 - Mild psoriasis.

- 1 - Psoriasis almost cleared.

- 0 - Clear (no lesion).

PASI (Psoriasis Area Severity Index)

The index is calculated as explained below.
Psoriasis Area and Severity Index

First introduced in 1978 (Fredriksson \& Pettersson)

Combines assessment of:

Area involved of 4 parts

1. Head \& Neck

2. Upper extremities

3. Trunk

4. Lower extremities

Characteristics of lesions in each of those 4 parts:

- Erythema (Redness)

- Induration (Thickness)

- Scaling
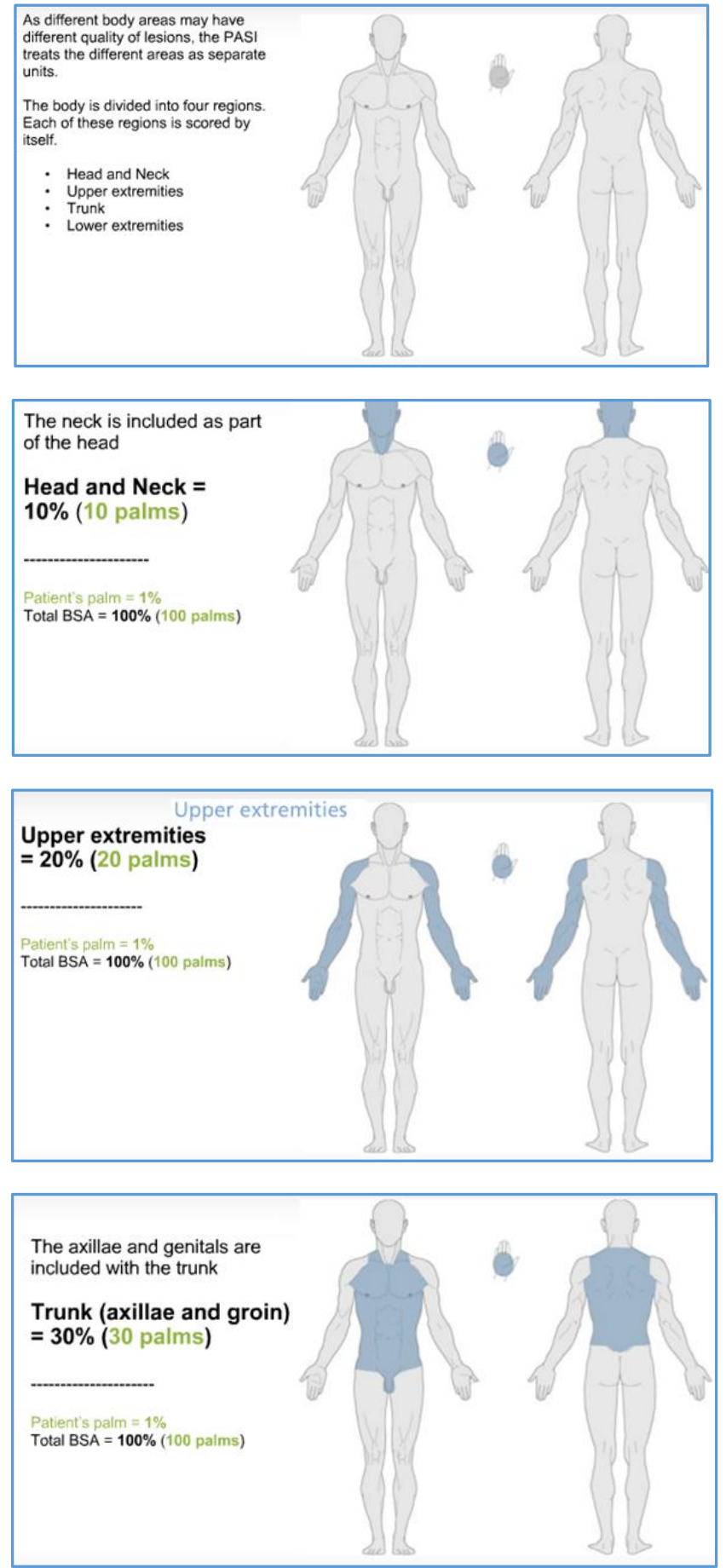


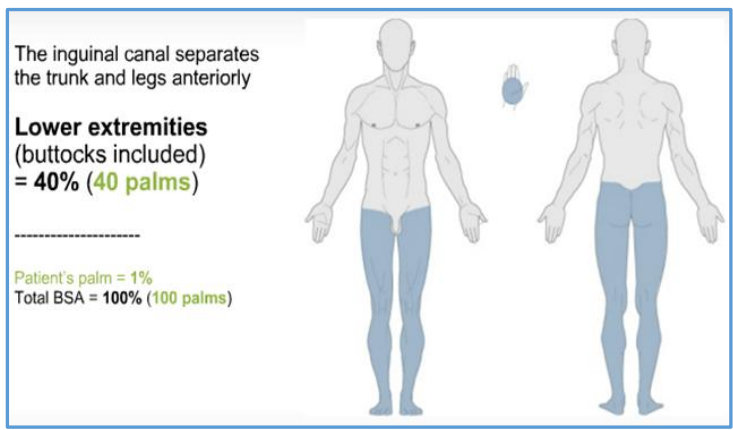

We need to specify the percentage of surface area covered by plaques in each
region and then assign the score accordingly:
$\begin{array}{rl}0 & \text { No involvement } \\ 1 & 1-9 \% \text { affected } \\ 2 & 10-29 \% \text { affected } \\ 3 & 30-49 \% \\ 4 & 50-69 \% \\ 5 & 70-89 \% \\ 6 & 90-100 \%\end{array}$

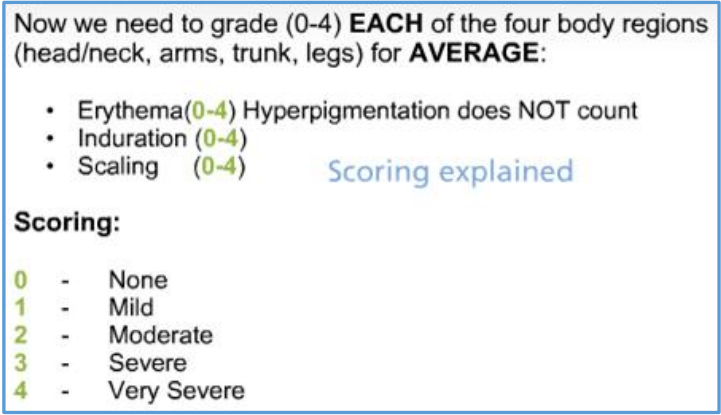

The following scoring system for erythema, induration, desquamation was used in study.
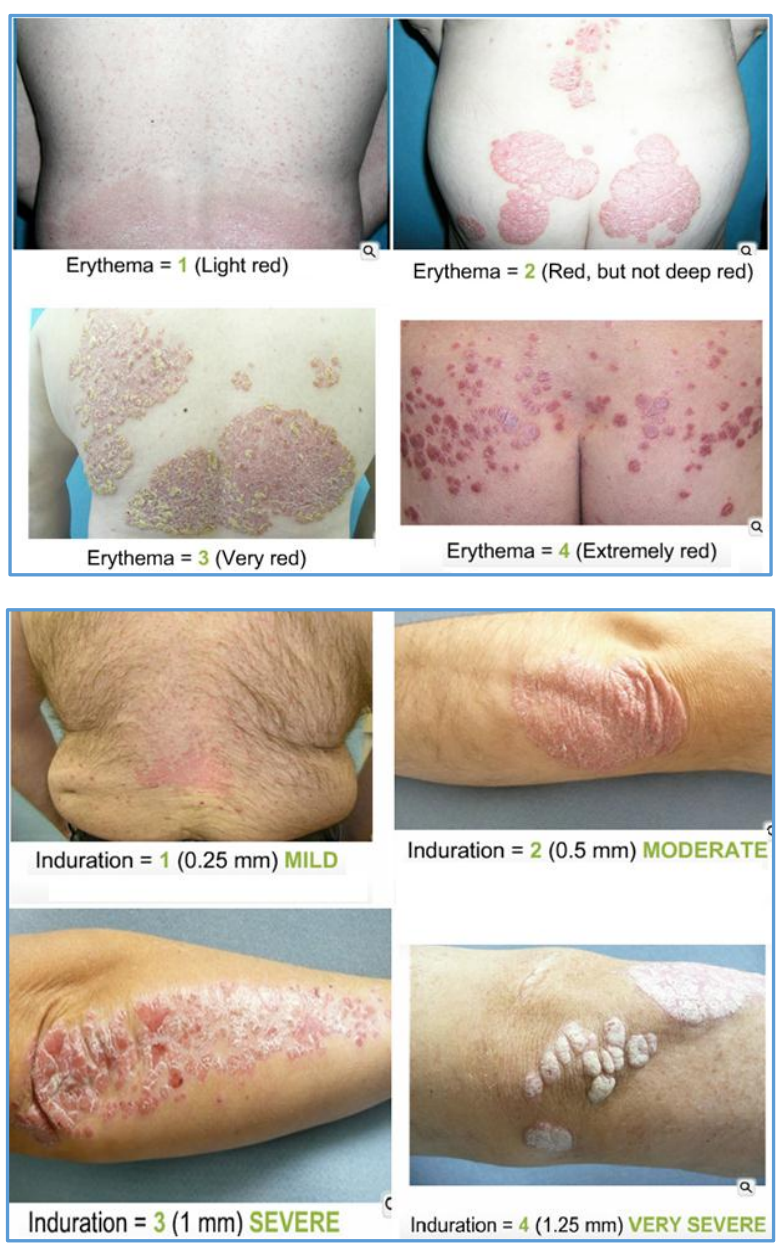

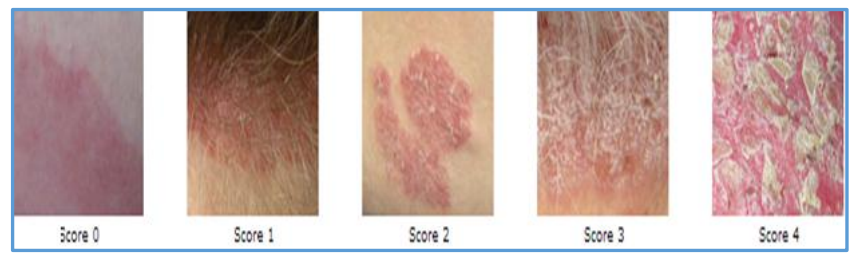

PLASI - PSORIASIS LOG-BASED AREA SEVERITY INDEX The Calculation is Identical to PASI, but a Different Score for the Extent of Lesions is used

- $0: 0 \%$

- 1 : $1-2 \%$

- $2: 3-5 \%$

- 3 : $6-10 \%$

- 4 : $11-21 \%$

- 5 : $22-46 \%$

- 6 : $47-100 \%$

PLASI $=0.1\left(\mathrm{E}_{\mathrm{H}}+\mathrm{I}_{\mathrm{H}}+\mathrm{D}_{\mathrm{H}}\right) \mathrm{A}_{\mathrm{H}}+0.2\left(\mathrm{E}_{\mathrm{U}}+\mathrm{I}_{\mathrm{U}}+\mathrm{D}_{\mathrm{U}}\right) \mathrm{A}_{\mathrm{U}}+$ $0.3\left(E_{T}+I_{T}+D_{T}\right) A_{T}+0.4\left(E_{L}+I_{L}+D_{L}\right) A_{L}$

Currently, there is still no consensus of what represents mild, moderate or severe plaque psoriasis. The definition proposed in this document to causing on the action to be taken may be considered as operational on,

Mild-to-Moderate Psoriasis: BSA < 10\%, PASI < 10, PGA 1 - 3.

Moderate to Psoriasis: BSA $<10.20 \%$, PASI 10 or more, PGA -4 . Moderate-to-Severe: BSA > 20, PASI > 20, PGA - 6 .

\section{RESULTS}

The present study is conducted on a total of 40 patients, who presented with chronic plaque psoriasis to Department of DVL, Osmania General Hospital, Hyderabad, from September 2014 to July 2015. During this period 28495 patients attended OPD with various skin complaints, out of which 10000 patients had papulosquamous disorders and patients had psoriasis. Patients had localised type of psoriasis, patients had chronic plaque psoriasis.

Out of these 40 patients were taken into study out of 40 cases, 15 were new cases, 25 cases took treatment but had relapses. All the 40 cases were subjected to thorough clinical examination and investigations. We performed the calculations of BSA, PGA, PASI, PLASI in the cases.

The results are tabulated as follows.

The different tables show the incidence.

\section{Absolute and Relative Differences}

Table 9 shows the mean results of BSA, PGA, PASI and PLASI before and after 8 weeks of treatment with methotrexate. The mean score before and after treatment therapy differed significantly ( $P$ <0.0001). Largest absolute difference was found with PLASI (35.1) followed by PASI (19), BSA (12.8), PGA (4). Largest relative difference was found with PLASI (86.32\%), PASI (84.16\%), PGA (80\%) and BSA (75.75\%).

\section{Regression Analysis}

Each possible correlation between parameters BSA, PGA, PASI and PLASI was calculated (Table 11). Strength of each correlation was compared. The correlation between PLASI and PASI ( $r=0.932$ ) was significantly stronger than correlation between any other two indices. Correlation between PLASI and BSA ( $r=0.593$ ) was found to be weakest among all other 
indices. Correlation with PGA with PASI and PLASI was weaker than correlation between PASI and PLASI. Further analysis of regression lines were carried out involving the $b$ (change in $y$ per unit change in $x$ ) and intercept a (value of $y$ when $x=0$ ). $\mathrm{Y}=\mathrm{a}+\mathrm{bx}$, where $\mathrm{b}$ is slope and $\mathrm{a}$ is intercept. The steepest slope (b) was found for regression between PLASI and PGA $(b=3.319)$. Regression between PLASI and BSA, PLASI and PGA had an intercept (a) greater than $5(a=9.834, a=5.113$ respectively) again in favour of PLASI; all other intercepts were less than 5 .

\begin{tabular}{|c|c|c|}
\hline Age in Yrs. & No. of Cases & (\%) \\
\hline $11-20$ & 2 & 5.8 \\
\hline $21-30$ & 8 & 23.52 \\
\hline $31-40$ & 14 & 41.17 \\
\hline $41-50$ & 9 & 26.47 \\
\hline $51-60$ & 1 & 2.9 \\
\hline $61-70$ & 0 & 0 \\
\hline Total & 34 & 100 \\
\hline Table 1: Age Distribution in Psoriasis Group \\
of Patients \\
\hline
\end{tabular}

The age distribution of our study is shown in Table No. 2 . Maximum number of cases were observed in $3^{\text {rd }}$ and $4^{\text {th }}$ decade and least in age $>60$ years.

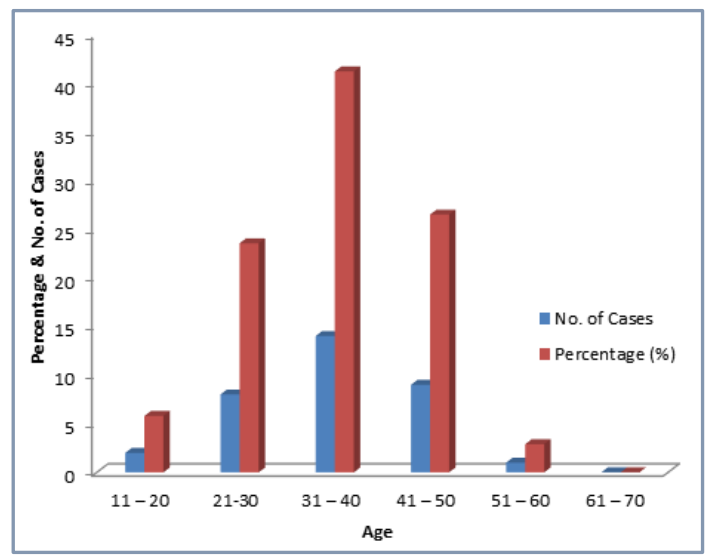

\begin{tabular}{|c|c|c|}
\hline Sex & No. of Cases & (\%) \\
\hline Males & 26 & 76.48 \\
\hline Females & 8 & 23.52 \\
\hline Total & 34 & 100 \\
\hline Table 2: Sex Distribution in Chronic Plaque \\
Psoriasis \\
\hline
\end{tabular}

Most of the patients in study were males $26(76.48 \%)$ and females are $8(23.52 \%)$.

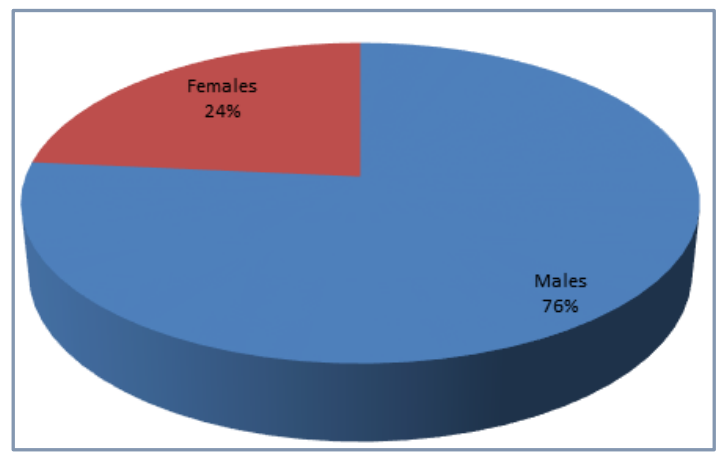

\begin{tabular}{|c|c|c|c|c|}
\hline $\begin{array}{c}\text { Score } \\
\text { of } \\
\text { BSA }\end{array}$ & $\begin{array}{c}\text { No. of } \\
\text { Patients } \\
\text { BSA 1 } \\
\text { (Before Rx) }\end{array}$ & (\%) & $\begin{array}{c}\text { No. of } \\
\text { Patients } \\
\text { BSA2 } \\
\text { (After Rx) }\end{array}$ & (\%) \\
\hline $0-5$ & 9 & 26.47 & 18 & 52.94 \\
\hline $6-10$ & 12 & 36.30 & 8 & 23.52 \\
\hline $11-15$ & 9 & 26.47 & 8 & 23.52 \\
\hline $16-20$ & 4 & 11.76 & 0 & 0 \\
\hline $21-25$ & 0 & 0 & 0 & 0 \\
\hline $26-30$ & 0 & 0 & 0 & 0 \\
\hline Total & 34 & 100 & 34 & 100 \\
\hline \multicolumn{2}{|c|}{ Table 3: Distribution of BSA Before and After Treatment } \\
\hline
\end{tabular}

Maximum no. of patients before treatment were in BSA score of 6-10: 12 (36.30\%). Maximum no. of patients after treatment were in BSA score of 0-5: 18 (52.94\%).

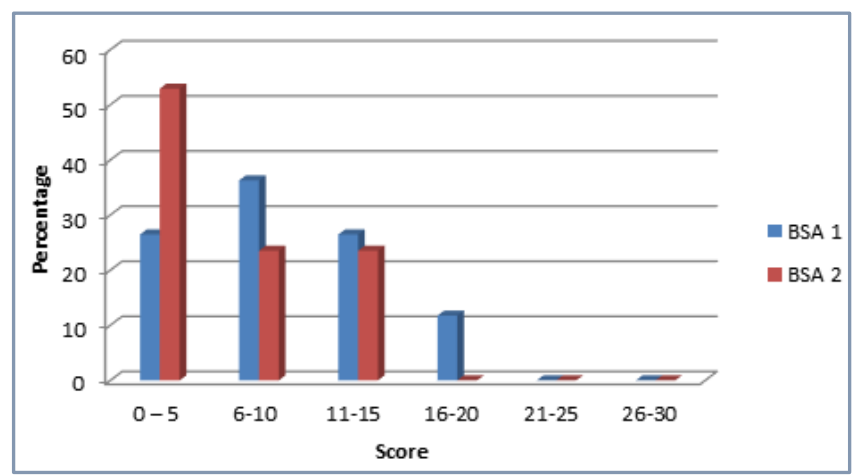

\begin{tabular}{|c|c|c|c|c|}
\hline Score & $\begin{array}{c}\text { No. of } \\
\text { Patients } \\
\text { PASI 1 } \\
\text { (Before Rx) }\end{array}$ & (\%) & $\begin{array}{c}\text { No. of } \\
\text { Patients } \\
\text { PASI 2 } \\
\text { (After Rx) }\end{array}$ & (\%) \\
\hline $0-$ & 5 & 14.70 & 26 & 76.47 \\
10 & 17 & 50.00 & 8 & 23.52 \\
\hline $11-20$ & 11 & 32.35 & 0 & 0 \\
\hline $21-30$ & 1 & 2.90 & 0 & 0 \\
\hline $31-40$ & 0 & 0 & 0 & 0 \\
\hline $41-50$ & 0 & 0 & 0 & 0 \\
\hline $51-60$ & 0 & 0 & 0 & 0 \\
\hline $61-72$ & 34 & 100 & 34 & 100 \\
\hline Total & \multicolumn{2}{|c|}{ Distribution of PASI Before and After Treatment } \\
\hline
\end{tabular}

Highest no. of patients before treatment with PASI were with score of 11-20: 17 (50\%). Highest no. of patients after treatment with PASI score were in $0-10: 26$ (76.47\%). No patients were with PASI score $>41$.

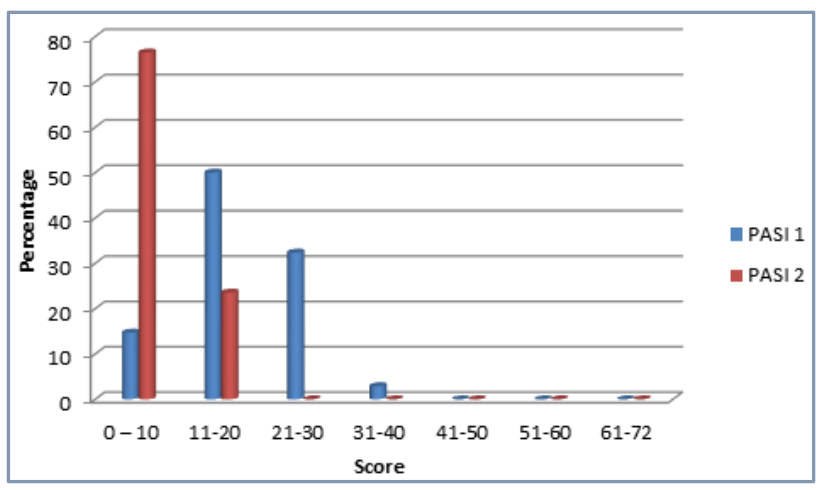




\begin{tabular}{|c|c|c|c|c|}
\hline Score & $\begin{array}{c}\text { No. of Patients } \\
\text { PLASI 1 } \\
\text { (Before Rx) }\end{array}$ & (\%) & $\begin{array}{c}\text { No. of Patients } \\
\text { PLASI 2 } \\
\text { (After Rx) }\end{array}$ & (\%) \\
\hline $0-10$ & 0 & 0 & 8 & 23.52 \\
\hline $11-20$ & 5 & 14.7 & 20 & 38.82 \\
\hline $21-30$ & 12 & 35.29 & 6 & 17.64 \\
\hline $31-40$ & 8 & 23.52 & 0 & 0 \\
\hline $41-50$ & 7 & 20.59 & 0 & 0 \\
\hline $51-60$ & 2 & 5.80 & 0 & 0 \\
\hline $61-72$ & 0 & 0 & 0 & 0 \\
\hline Total & 34 & 100 & 34 & 100 \\
\hline \multicolumn{7}{|c|}{ Table 4: Distribution of PLASI Before and After } \\
Treatment
\end{tabular}

Highest no. of patients before treatment were found in PLASI 21-30: 12 (35.29\%) and after treatment were in PLASI 11-20: $20(38.20 \%)$. No patients were in the study having score $>61$.

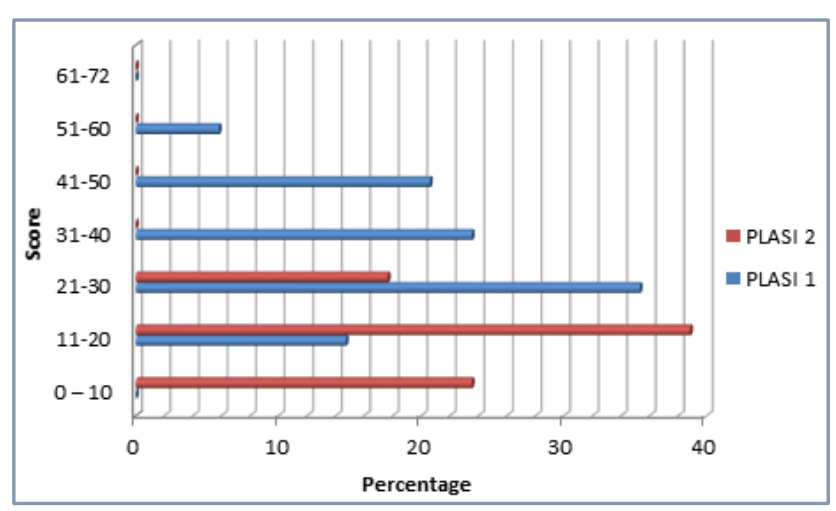

\begin{tabular}{|c|c|c|c|c|c|}
\hline 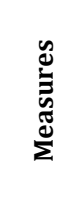 & 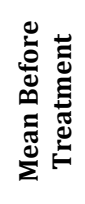 & 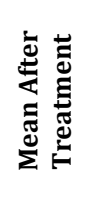 & 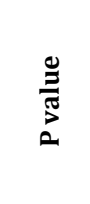 & 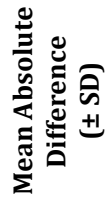 & 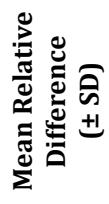 \\
\hline BSA & 9.57 & 6.11 & $<10-4$ & $\begin{array}{c}3.6 \pm \\
3.2\end{array}$ & $\begin{array}{c}34.75 \pm \\
23.12\end{array}$ \\
\hline PGA & 4.68 & 3.00 & $<10-4$ & $\begin{array}{c}1.68 \pm \\
1.12\end{array}$ & $\begin{array}{c}35.83 \pm \\
22.49\end{array}$ \\
\hline PASI & 17.27 & 7.97 & $<10-4$ & $\begin{array}{c}9.31 \pm \\
5.75\end{array}$ & $\begin{array}{c}51.10 \pm \\
21.56\end{array}$ \\
\hline PLASI & 31.07 & 15.07 & $<10-4$ & $\begin{array}{c}15.12 \pm \\
8.78\end{array}$ & $\begin{array}{c}49.20 \pm \\
19.80\end{array}$ \\
\hline
\end{tabular}

SD, Standard Deviation.

Highest score of mean before and after treatment; absolute difference and relative difference in study was found with PLASI.

\begin{tabular}{|c|c|c|}
\hline Index & $\begin{array}{c}\text { Largest Absolute } \\
\text { Difference } \\
\text { (Delta) }\end{array}$ & $\begin{array}{c}\text { Largest Relative } \\
\text { Difference } \\
\text { (Delta \%) }\end{array}$ \\
\hline BSA & 12.80 & 75.25 \\
\hline PGA & 4 & 80.00 \\
\hline PASI & 19 & 84.16 \\
\hline PLASI & 35.10 & 86.32 \\
\hline \multicolumn{2}{|c|}{ Table 6: Comparison of Absolute and Relative } \\
Differences of Various Indices
\end{tabular}

Largest absolute difference and relative difference was found in PLASI, i.e. 35.10 and 86.32 respectively. Least was found in BSA (75.25\%).

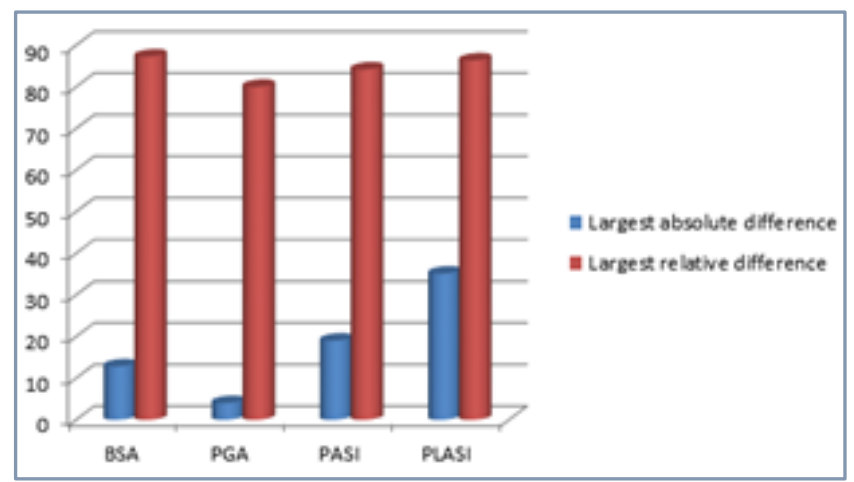

\begin{tabular}{|c|c|c|}
\hline Measures & $\begin{array}{c}\text { Regression } \\
(\mathbf{y}=\mathbf{a}+\mathbf{b} \mathbf{x})\end{array}$ & $\begin{array}{c}\text { Co-Efficient of } \\
\text { Correlation (r) }\end{array}$ \\
\hline PLASI & $5.113+3.319 \times$ PGA & 0.676 \\
\hline PASI & $0.585+2.462 \times$ PGA & 0.760 \\
\hline BSA & $-0.455+2.187 \times$ PGA & 0.637 \\
\hline PLASI & $9.894+0.848 \times$ BSA & 0.593 \\
\hline PLASI & $3.812+1.413 \times$ PASI & 0.932 \\
\hline PASI & $3.824+0.679 \times$ BSA & 0.720 \\
\hline \multicolumn{3}{|c|}{ Table 7: Linear Regression and Correlation between } \\
Each of the Measures \\
\hline
\end{tabular}

- $\quad \mathrm{y}$ is dependent variable.

- $a$ is intercept

- $b$ is slope

- $\mathrm{x}$ is constant.

- $r$ is co-efficient of correlation.

Steepest slope is found in regression with PLASI and PGA indicating that PLASI can differentiate levels of severity more accurately than PGA.

Regression between PLASI and PGA, PLASI and BSA have intercept greater than five $(a=5.113, a=9.894)$ respectively again is in favour of PLASI.

\section{DISCUSSION}

BSA and PGA are older measures to grade severity of psoriasis. PASI is the most commonly used measure to investigate the severity and coverage of psoriasis, and the improvement after therapy. The "PASI concept," has made possible many scientific contributions within the last 29 years. All the measures (PASI, PLASI, PGA and BSA) show a very high correlation with each other. In study by Tilo Hensler et al all the measures (PASI, PLASI, SAPASI and BSA) show a very high correlation with each other. The correlation between PASI and PLASI in this study was higher than that found by Hensler et $\mathrm{al}, 4,5$ Feldman et $\mathrm{al}, 6,7,8$ ( $\mathrm{r}=0.932$ vs. $\mathrm{r}=0.91$ vs. $\mathrm{r}=0.77$ ) respectively. In our study, steep regression slope $(b=3.314)$ indicate PLASI can differentiate levels of severity more accurately than PGA, PASI. For example, one point improvement of PGA is equivalent to 3.314 point improvement of PLASI. In study of Hensler et al, ${ }^{4}$ the steep regression slope $(b=1.48)$ indicates that PLASI can differentiate levels of severity more accurately than PASI. The better differentiation of PLASI is a result of the logarithmic distribution in the rating of the body area affected. In our study when considering an 
identical clinical improvement, a better differentiation is achieved using PLASI. An improvement by therapy of 50\% PLASI corresponds to a change of $13.56 \%$ of PGA; when considering with PASI it is $32.69 \%$. In Hensler et al,4 DPLASI $50 \%$ corresponded to $33.8 \%$ of DPASI. In study conducted by C. C. Jackobson et $\mathrm{al}^{9}$ and Jemec et al, ${ }^{10}$ clinical improvements under the grading systems using PLASI translated into greater percentage changes than calculated using the Delta PASI formula. Specifically, the Delta PASI 50 translated to a Delta PLASI 57·2; Delta PASI 75 was equivalent to Delta PLASI 85.7. Importantly, Delta PASI tended to be systematically lower than patients \& \#39; self-assessment. While Delta PLASI better matched patients \& \#39; self-assessments. Based on comparison with two above studies, we conclude that PLASI is better than PASI in showing clinical improvement.

The influence of the logarithmic scale can be demonstrated as follows (Assuming the severity of erythema, infiltration and desquamation does not change). In two patients, if the area affected by psoriasis has been reduced by therapy in all distinct sites from $25 \%$ and $80 \%$ respectively to $10 \%$ in both cases. Using PASI, the improvements are $0 \%$ (No change in BSA score) and 20\% respectively, whereas PLASI shows improvements of $16.7 \%$ (BSA score change from five to three) in the first case and $50 \%$ (BSA score change from six to two) in the second case. Therefore, the first case is more accurately measured by PLASI. When improvement is only poor and the patient's BSA remains in the $100-50 \%$ interval; however, PASI is able to differentiate therapeutic "success," whereas PLASI cannot. In our study, the slope of the regression for PLASI $(b=$ 3.319) vs. PASI $(b=2.462)$ indicates that PLASI is more accurate than PASI. In the regression analyses, all other slopes were less than unity indicating that the severity differentiation was inferior, especially when BSA was involved in the analysis. In study of Hensler et $\mathrm{al}, 4$ the slope of the regression for PLASI $(b=1.48)$ vs. SAPASI $(b=1.32)$ indicates that PLASI is more accurate than SAPASI. In the regression analyses, all other slopes were less than unity indicating that the severity differentiation was inferior, especially when BSA was involved in the analysis.

In our study comparison of BSA with PGA ( $r=0.630)$ meaning to correlate moderately with PGA. Validity was only tested with the PGA, which correlated strongly (Langley and Ellis, 2004.11 The BSA was least improved after 2 weeks treatment compared with other psoriasis parameters, which is negative for responsiveness. The clinical assessed BSA did not differ statistically from objectively assessed BSA, for instance with computer-based image analysis in two studies (Kanthraj et al 1997 Ormerod et al, 1997). ${ }^{12}$

However, several other studies showed that patients and clinicians significantly overestimate the affected area, especially in mild cases and when untrained (Ramsay and Lawrence, 19911; Tiling-Grosse and Rees, 199313; Savolainen et al 1997, 199814\&15; Yune et al, 200316; Kreft et al, 2006). ${ }^{17}$

The correlation coefficient between BSA assessed by dermatologists and patients ranged from r:0.38-0.82 (Feldman et al 1996, 2005; Fleischer, Jr et al, 199910; Szepietowski et al 200118; Sampogna et al 2003). ${ }^{19}$ In present study, co-efficient of correlation between PASI and PGA was $\mathrm{r}=0.760, \mathrm{p}<0.0001$ suggesting moderate strength of correlation.

In study conducted by J. Berth Jones et $\mathrm{al}^{20}$ found that PGA and PASI moderately correlated $(\mathrm{r}=0.79, \mathrm{p}<0.001)$
Dermatology revealed study which studied efficacy of efalizumab in patients with moderate-to-severe psoriasis after 16 weeks of treatment patients with PASI 75 were $71 \%$ compared to PGA 0,1 showing $62 \%$ showing that PASI show better improvement than PGA.

\section{CONCLUSION}

1. There are large no. of indices to assess psoriasis severity and response of which few are in use.

2. PASI is one of the most extensively studied and used index.

3. PGA is simpler index, but lacks standardisation.

4. BSA is simpler and subjective. It is least sensitive in comparison with other indices.

5. PLASI is the best sensitive indicator of disease severity in mild-to-moderate psoriasis.

6. PASI is better than PLASI in psoriasis when improvement is poor and when BSA is in $100-50 \%$ interval.

\section{REFERENCES}

1. Ramsay B, Lawrence CM. Measurement of involved surface area in patients with psoriasis. Br J Dermatol 1991;124(6):565-70.

2. Fredriksson T, Lassus A, Salde L. Reproducibility of clinical trials of topical glucocorticosteroids. Int J Dermatol 1983;22(9):536-9.

3. Fredriksson T, Pettersson U. Severe psoriasis-oral therapy with a new retinoid. Dermatologica 1978;157(4):238-44.

4. Andressen C, Henseler T. Inheritance of psoriasis. Analysis of 2035 family histories. Hautarzt 1982;33(4):214-7.

5. Henseler T, Christophers E. Psoriasis of early and late onset: characterization of two types of psoriasis vulgaris. J Am Acad Dermatol 1985;13(3):450-6.

6. Feldman SR, Clark AR, Venkat AP, et al. The selfadministered psoriasis area and severity index provides an objective measure of psoriasis severity. Br J Dermatol 2005;152(2):382-3.

7. Feldman SR, Fleischer AB, Reboussin DM, et al. The self administered psoriasis area and severity index is valid and reliable. J Invest Dermatol 1996;106(1):183-6.

8. Feldman SR, Krueger GG. Psoriasis assessment tools in clinical trials. Ann Rheum Dis 2005;64(Suppl 2):ii65-73.

9. Jacobson CC, Kimball AB. Rethinking the psoriasis area and severity index: the impact of area should be increased. Br J Dermatol 2004;151(2):381-7.

10. Jemec GB, Wulf HC. The applicability of clinical scoring systems: SCORAD and PASI in psoriasis and atopic dermatitis. Acta Derm Venereol 1997;77(5):392-3.

11. Langley RG, Ellis CN. Evaluating psoriasis with psoriasis area and severity index, psoriasis global assessment, and lattice system physician's global assessment. J Am Acad Dermatol 2004;51(4):563-9.

12. Kanthraj GR, Srinivas CR, Shenoi SD, et al. Comparison of computeraided design and rule of nines methods in the evaluation of the extent of body involvement in cutaneous lesions. Arch Dermatol 1997;133(7):922-3.

13. Tiling-Grosse S, Rees J. Assessment of area of involvement in skin disease: a study using schematic figure outlines. Br J Dermatol 1993;128(1):69-74. 
14. Savolainen L, Kontinen J, Roning J, et al. Application of machine vision to assess involved surface in patients with psoriasis. Br J Dermatol 1997;137(3):395-400.

15. Savolainen L, Kontinen J, Alatalo E, et al. Comparison of actual psoriasis surface area and the psoriasis area and severity index by the human eye and machine vision methods in following the treatment of psoriasis. Acta Derm Venereol 1998;78(6):466-7.

16. Yune Y-M, Park SY, Oh HS, et al. Objective assessment of involved surface area in patients with psoriasis. Skin Res Technol 2003;9(4):339-42.

17. Kreft S, Kreft M, Resman A, et al. Computer-aided measurement of psoriatic lesion area in a multicenter clinical trial-comparison to physician's estimations. J Dermatol Sci 2006;44(1):21-7.
18. Szepietowski JC, Sikora M, Pacholek T, et al. Clinical evaluation of the self-administered psoriasis area and severity index (SAPASI). Acta Dermatovenerologica Alpina, Panonica et Adriatica 2001;10(3):79-83.

19. Sampogna F, Sera F, Mazzotti E, et al. Performance of the self-administered psoriasis area and severity index in evaluating clinical and socio demographic subgroups of patients with psoriasis. Arch Dermatol 2003;139(3):353-8.

20. Berth-Jones J, Grotzinger K, Rainville C, et al. A study examining inter and intra rater reliability of three scales for measuring severity of psoriasis: psoriasis area and severity index, physician's global assessment and lattice system physician's global assessment. Br J Dermatol 2006;155(4):707-13. 